\title{
Resuscitation of 'non-culturable' cells from aged cultures of Campylobacter jejuni
}

\author{
R. A. Bovill and B. M. Mackey \\ Author for correspondence: R. A. Bovill. Tel: +44 1189357230 . Fax: +44 1189357222. \\ e-mail: Bovill@BBSRC.ac.uk
}

Microbiology Department, Institute of Food Research, Earley Gate, Whiteknights Road, Reading RG6 6BZ, UK

\begin{abstract}
When stationary phase batch cultures of Campylobacter jejuni were stored in sealed flasks under static conditions, viable numbers declined from $2 \times 10^{9}$ c.f.u. $\mathrm{ml}^{-1}$ to around $10^{3}-10^{6}$ c.f.u. $\mathrm{ml}^{-1}$ within $4-6$ weeks. When the aged cultures were sparged with a microaerobic gas mixture, there was a rapid increase in viable numbers accompanied by a change from predominantly coccoid to vibrioid morphology. The most probable number (MPN) technique was used to distinguish resuscitation of injured or dormant cells from multiplication of residual viable cells. MPN estimates using fresh Brucella broth containing $0.2 \%$ mucin revealed that plate counts underestimated the true viable count by up to 23 -fold. The experiments clearly demonstrated that a proportion of surviving cells in aged cultures were in an injured or latent state that prevented growth on agar plates. It is possible that the size of this fraction is greater than was demonstrated and that much higher recoveries would be obtained under other recovery conditions. Nevertheless, from presently available evidence, it must be concluded that the size of the latent fraction is quite small and that most of the increase in count that occurs on regassing a spent culture comes from multiplication of residual viable cells.
\end{abstract}

Keywords: Campylobacter jejuni, viable but non-culturable cells, resuscitation, fluorogenic substrates

\section{INTRODUCTION}

Under conditions that are unfavourable for growth, cells of Campylobacter jejuni change from their characteristic vibrioid morphology to a coccoid form (Rhoades, 1954). This transition occurs as a normal event in the stationary phase of growth and also when exponentially growing cells are transferred to starvation conditions in buffer or water (Rollins \& Colwell, 1986). The conversion takes place more rapidly under aerobic than anaerobic conditions (Moran \& Upton, 1987a, b). The formation of coccoid cells has been reported in other curved or vibrioid bacteria including Campylobacter coli (Jacob et al., 1993), Helicobacter pylori (Bode et al., 1993) and Vibrio vulnificus (Oliver et al., 1991), and a conversion to a more rounded cell shape has also been described in stationary phase Escherichia coli (Lange \& HenggeAronis, 1991).

During the conversion to coccoid morphology in $C$. jejuni, there is a rapid loss of viability as measured by

Abbreviations: CTC, 5-cyano-2,3-ditolyltetrazolium chloride; DAPI, 4',6diamidino-2-phenylindole; DVC, direct viable count; MPN, most probable number; VBNC, viable but non-culturable. plate counts on agar (Rollins \& Colwell, 1986). However, viability measured by other criteria may decline more slowly. For example, numbers of cells able to elongate in response to nutrients in the presence of an inhibitor of DNA synthesis, or that can reduce tetrazolium salts, are often orders of magnitude higher than plate counts (Boucher et al., 1994; Rollins \& Colwell, 1986). This has led to the suggestion that coccoid cells are viable, but unable to replicate on media that normally support growth.

The existence of viable but non-culturable (VBNC) forms of C. jejuni and other bacteria would explain why infections have occurred in the absence of a detectable environmental source (Colwell et al., 1985). However, the evidence for the infectivity of non-culturable C. jejuni is controversial. Rollins \& Colwell (1986) reported that non-culturable cells of C. jejuni in a stream water microcosm could be recovered by animal passage. This was confirmed by Jones et al. (1991), who showed that two of four strains of C. jejuni that were unculturable after storage in water for 6 weeks could be recovered by feeding to suckling mice; and by Stern $e t$ al. (1994), who found that a small proportion of 1-d-old chicks became colonized by $C$. jejuni after feeding with 
aqueous suspensions containing no viable cells. Cells rendered unculturable by freeze injury were similarly recovered by animal passage (Saha et al., 1991). However, others have produced contrary results. Medema $e t$ al. (1992) were unable to recover cells that were nonculturable, but which elongated in response to nutrients, by feeding 1-d-old chicks or by passage through the allantoic fluid of embryonated eggs. Beumer $e t$ al. (1992) were unable to recover non-culturable cells by inoculation into simulated gastric, ileal or colonic environments, or by feeding to rats, rabbits or human volunteers.

In view of the potential epidemiological importance of VBNC cells, it is important to establish unequivocally that they exist and to understand the processes leading to the loss and subsequent recovery of culturability. Since animal experiments are difficult to control, it would be desirable to develop in vitro systems for studying the recovery of culturability. A convenient method for Vibrio vulnificus, involving temperature shifts to and from $5{ }^{\circ} \mathrm{C}$ for inducing the formation and resuscitation of non-culturable cells, was described by Nilsson et al. (1991). Using this system in an estuarine environment, it was demonstrated that viable cells could be recovered from suspensions that initially contained no detectable organisms (Oliver et al., 1995). Other experiments with the system suggested that the increase in viable numbers observed during temperature upshift was caused by multiplication of residual culturable cells rather than by true resuscitation (Weichart et al., 1992; Weichart \& Kjelleberg, 1996). Kell and co-workers showed unequivocally that starved non-culturable cells of the Gram-positive organism Micrococcus luteus could be recovered in growth medium, provided that some filtered medium from a culture growing in late exponential phase was added (Kaprelyants et al., 1994) or that some viable cells were present (Votyakova et al., 1994). It was concluded that medium from exponentially growing cultures may promote resuscitation by overcoming the effect of an antibacterial factor that otherwise caused self-poisoning of dormant cells during resuscitation (Mukamolova et al., 1995).

During studies of the survival of C. jejuni in the stationary phase, we discovered conditions that led to a rapid increase in viable numbers in aged cultures, accompanied by a change from predominantly coccoid to vibrioid morphology. This paper investigates the basis of this phenomenon.

\section{METHODS}

Strains and culture conditions. Campylobacter jejuni NCTC 11351 and 11168 were stored frozen at $-70^{\circ} \mathrm{C}$ on porous plastic beads (Pro-Lab Diagnostics). Cultures were grown at $37^{\circ} \mathrm{C}$ in shaking culture in Brucella broth (Difco) containing a growth supplement (FBP; $0.9 \mathrm{mM}$ ferrous sulphate, $1.3 \mathrm{mM}$ sodium metabisulphite, $2.3 \mathrm{mM}$ sodium pyruvate; BBFBP). A microaerobic atmosphere $\left[\mathrm{CO}_{2} / \mathrm{N}_{2} / \mathrm{O}_{2}(10: 85: 5\right.$, by vol.) $]$ was generated using Anaerocult $\mathrm{C}$ sachets (Merck) and anaerobe jars. Medium was freshly prepared in all cases. Later experiments were conducted in a Variable Atmosphere Incubator (VAIN; Don Whitley Scientific).

Chemicals. 5-Cyano-2,3-ditolyltetrazolium chloride (CTC) was purchased from Park Scientific, 1,4-diazabicyclo[2.2.2]octane was from Aldrich and 4',6-diamidino-2-phenylindole (DAPI), Br-c-GMP, c-AMP, c-GMP, insulin and hog gastric mucin were from Sigma-Aldrich.

Dilution plate counts. Samples were diluted in maximal recovery diluent (Oxoid) and spread on Mueller-Hinton plates supplemented with FBP and $5 \%(\mathrm{v} / \mathrm{v})$ sheep blood (MHABFBP). Plates were incubated microaerobically in an anaerobe jar at $37^{\circ} \mathrm{C}$ and examined after 2 and $7 \mathrm{~d}$.

Determination of percentages of vibrioids and cocci. To a $1 \mathrm{ml}$ sample, $0.1 \mathrm{ml}$ formaldehyde solution $(37 \%, \mathrm{w} / \mathrm{v})$ was added and the sample was left for $20 \mathrm{~min}$. A drop was then applied to a microscope slide, air-dried and fixed with methanol for $2 \mathrm{~min}$. It was then Gram-stained using carbol fuchsin as the counter-stain. Approximately 1000 cells were then counted, noting the type as vibrioid or coccoid, using a Nikon Microphot-SA microscope equipped with $a \times 100$ oil immersion objective lens.

Total cell counts. Samples were taken and placed in a Helber counting chamber (Merck). The chamber was examined using phase contrast and the $\times 40$ objective of a Nikon MicrophotSA microscope and 500-1000 cells were counted to achieve an estimate of cell concentration. An estimate of error of counting was obtained by filling the chamber seven times with a culture sample and counting the number of cells in 10 small squares each time. The standard deviation was then calculated for the mean values of each filling.

Examination of cells for metabolic activity using CTC. CTC (44 $\mathrm{mM}$ ) was made up as a stock solution in distilled water and filter-sterilized ( $0.02 \mu \mathrm{m}$ 'Anotop' filter). Solutions were stored in darkened containers at $4{ }^{\circ} \mathrm{C}$ and used on the same day as preparation.

Cell samples were diluted 1 in 100 in MRD and $1 \mathrm{ml}$ amounts were filtered through black polycarbonate membrane filters (Nucleopore; $0 \cdot 1 \mu \mathrm{m}$ ). Cells were washed twice with, and then overlaid with, $1 \mathrm{ml}$ modified Dulbecco's phosphate buffer (without calcium chloride and containing $22.7 \mathrm{mM}$ sodium pyruvate). CTC solution $(100 \mu \mathrm{l})$ was then added and the cells were incubated in the dark for $40 \mathrm{~min}$. They were then washed twice with, and overlaid with, $1 \mathrm{ml}$ citrate buffer ( $\mathrm{pH} \mathrm{3.4)}$ and $100 \mu$ DAPI solution was added ( $4 \mathrm{mM}$ in dry DMSO). After a further $30 \mathrm{~min}$ incubation in the dark, the cells were washed three times with citrate buffer and the filters were dried. They were then mounted in 1,4-diazabicyclo[2.2.2] octane solution in glycerol $(40 \%, \mathrm{v} / \mathrm{v})$.

Slides were examined using epifluorescence and the number of cells fluorescing with DAPI and CTC was determined and counted as described previously (Bovill et al., 1994).

Scanning electron microscopy. Broth samples were fixed using $3.7 \%(\mathrm{w} / \mathrm{v})$ formaldehyde, diluted in MRD and filtered through $0 \cdot 1 \mu \mathrm{m}$ polycarbonate membrane filters (Nucleopore). Cells were washed with Dulbecco's phosphate buffer, dehydrated using a graded series of alcohol dilutions and critical point dried. After gold sputtering, small portions of filter were examined using a Hitachi S-570 scanning electron microscope.

Most probable number (MPN) counts. To determine whether the increase in count during regassing was due to regrowth or 
resuscitation, plate counts were compared with MPN counts (see Results). Samples of aged culture were taken prior to the recommencement of gassing and MPN dilutions were performed. Diluent for the MPN counts was (a) freshly prepared BBFBP; (b) filtered spent broth from the same culture as the sample; or (c) filtered broth from an exponentially growing culture of the same test strain. A number of substances known to initiate changes in cell morphology or to promote growth from small inocula in other organisms (Csaba, 1994; Aono et al., 1978; Rasmussen et al., 1996) and the chemoattractants fucose and mucin (Hugdahl et al., 1988) were also examined. Thus, cAMP, cGMP, Br-cGMP, fucose and insulin were made up in deionized water, filter-sterilized and added to freshly prepared Brucella broth to give a final concentration of $1 \mathrm{mM}$. Mucin was added to Brucella broth at $0.2 \%$ and autoclaved. Samples of cell suspension were decimally diluted in appropriate recovery medium and $200 \mu$ l amounts of each dilution were added to the wells of each column of microtitre plates to give eight replicate dilution series. Plates were sealed with plastic film (perforated to allow gaseous transfer) and incubated for $48 \mathrm{~h}$. After incubation, $50 \mu \mathrm{l}$ amounts from each well were plated onto MHABFBP and wells were noted as positive or negative according to growth on the plates after $48 \mathrm{~h}$. Plate preparation, dilutions and incubation were performed in a VAIN incubator.

Batch cultivation, inactivation and recovery. Cells were inoculated from an exponentially growing culture into a $500 \mathrm{ml}$ conical flask containing Brucella broth plus FBP. The flask was equipped with inlet and outlet tubes which allowed a microaerobic gas mixture $\left[\mathrm{CO}_{2} / \mathrm{N}_{2} / \mathrm{O}_{2}(10: 85: 5\right.$, by vol.) $]$ to be bubbled through the broth. A third tube allowed broth samples to be removed without unduly disturbing the gas atmosphere in the flask. In the initial experiments, cultures were gassed at $3 \mathrm{~h}$ intervals. In later experiments, the procedure was changed and a continuous gentle stream of gas (approximately $5 \mathrm{ml} \mathrm{min}^{-1}$ ) was passed through the medium. The flask was contained in a shaking water bath at $37^{\circ} \mathrm{C}$ unless otherwise stated. Samples were taken at intervals and growth was monitored by plate counting.

After stationary phase had been reached the flask was sealed and placed on a shaking platform at $37^{\circ} \mathrm{C}$ for $2-4$ weeks. After this time, a sample was taken for counting and gassing was recommenced. Additional samples were taken during regassing.

\section{RESULTS}

\section{Increase in viable counts during regassing of $C$. jejuni 11351}

When sparging of stationary phase cultures of C. jejuni was discontinued, viable numbers, as determined by plate counts, progressively decreased, until after 2-4 weeks numbers had declined to between $10^{3}$ and $10^{6}$ c.f.u. $\mathrm{ml}^{-1}$. When the culture was subsequently regassed, plate counts increased exponentially until viable numbers approached those present when the culture originally entered the stationary phase (Fig. 1). Thereafter, numbers decreased rapidly again. The $\mathrm{pH}$ immediately before regassing was 6.2 compared to 6.9 when inoculated and the dissolved oxygen content was less than $0.5 \%$ of the air-saturated value.

The apparent doubling time after regassing varied

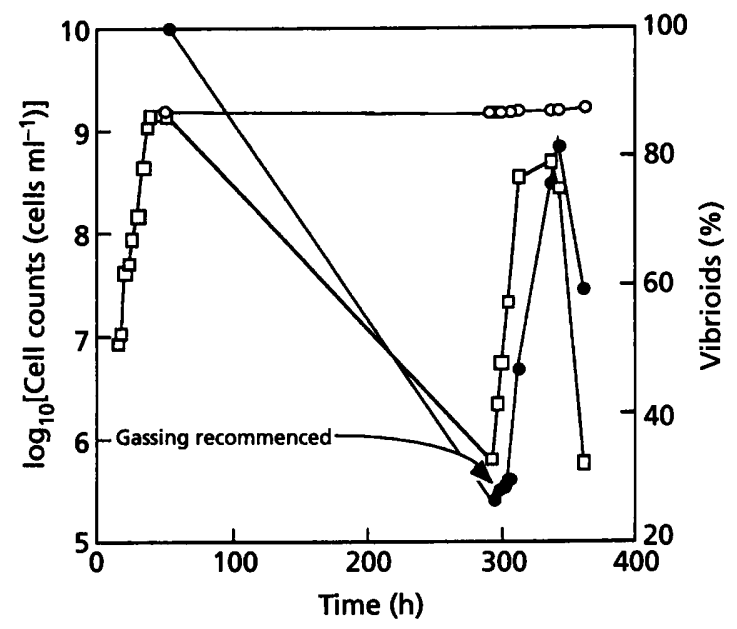

Fig. 1. Increase in plate counts and percentage of vibrioids in aged spent broth. $\square$, Plate counts (c.f.u. $\mathrm{ml}^{-1}$ ); 9 , percentage of vibrioids; $O$, total counts.

between experiments, depending on conditions. When the culture was sparged intermittently (every $3 \mathrm{~h}$ ), doubling times varied between 1.4 and $5.5 \mathrm{~h}$. Continuously sparged cultures had doubling times of between 1.2 and $3.3 \mathrm{~h}$. Doubling times were inversely proportional to the initial number of plateable cells present in the culture at the start of regassing.

\section{Change in morphological composition of cultures}

The percentage of vibrioids in cultures rose quickly during regassing after a brief lag (Fig. 1). The percentages of vibrioids and the viable counts at the start of regassing in different experiments was somewhat variable and depended to a large extent on the length of time that the culture had been stored. Nevertheless, the same trend was apparent in all cases (Table 1). The percentages of vibrioids and cocci were determined using Gram staining (Fig. 2a, b) and the large differences in size and shape of coccoid cells gave rise to some concern as to the accuracy of the determination. Selected samples were, therefore, checked using scanning electron microscopy, which confirmed the results obtained by Gram staining.

\section{Changes in single cell metabolic activity and 'direct viable counts' during regassing}

The addition of nalidixic acid to growing cultures of susceptible cells inhibits cell division but not growth, and viable cells, therefore, continue to elongate in the presence of nutrients. Enumeration of elongated cells has been widely used as a direct method for estimating viability (Kogure et al., 1979).

A comparison of viable cell numbers as determined by plate counting and those obtained by the Kogure 'direct 
Table 1. Plate counts and percentage of vibrioids before and after regassing

\begin{tabular}{|lccccc|}
\hline $\begin{array}{l}\text { Expt } \\
\text { no. }\end{array}$ & Strain & $\begin{array}{c}\text { Initial plate } \\
\text { count }\end{array}$ & $\begin{array}{c}\text { Final plate } \\
\text { count }\end{array}$ & $\begin{array}{c}\text { Initial } \\
\text { percentage } \\
\text { of vibrioids }\end{array}$ & $\begin{array}{c}\text { Final } \\
\text { percentage } \\
\text { of vibrioids }\end{array}$ \\
\hline 1 & 11351 & $5 \cdot 60 \times 10^{5}$ & $5 \cdot 00 \times 10^{8}$ & 26 & 82 \\
2 & 11351 & $6 \cdot 95 \times 10^{5}$ & $1 \cdot 70 \times 10^{9}$ & 7 & 62 \\
3 & 11351 & $2 \cdot 20 \times 10^{3}$ & $2 \cdot 00 \times 10^{9}$ & 5 & 57 \\
4 & 11351 & $2 \cdot 40 \times 10^{6}$ & $3.60 \times 10^{8}$ & 7 & 77 \\
5 & 11168 & $7 \cdot 60 \times 10^{4}$ & $1 \cdot 10 \times 10^{9}$ & 9 & 61 \\
6 & 11168 & $1 \cdot 60 \times 10^{4}$ & $6.60 \times 10^{8}$ & 18 & 67 \\
\hline
\end{tabular}
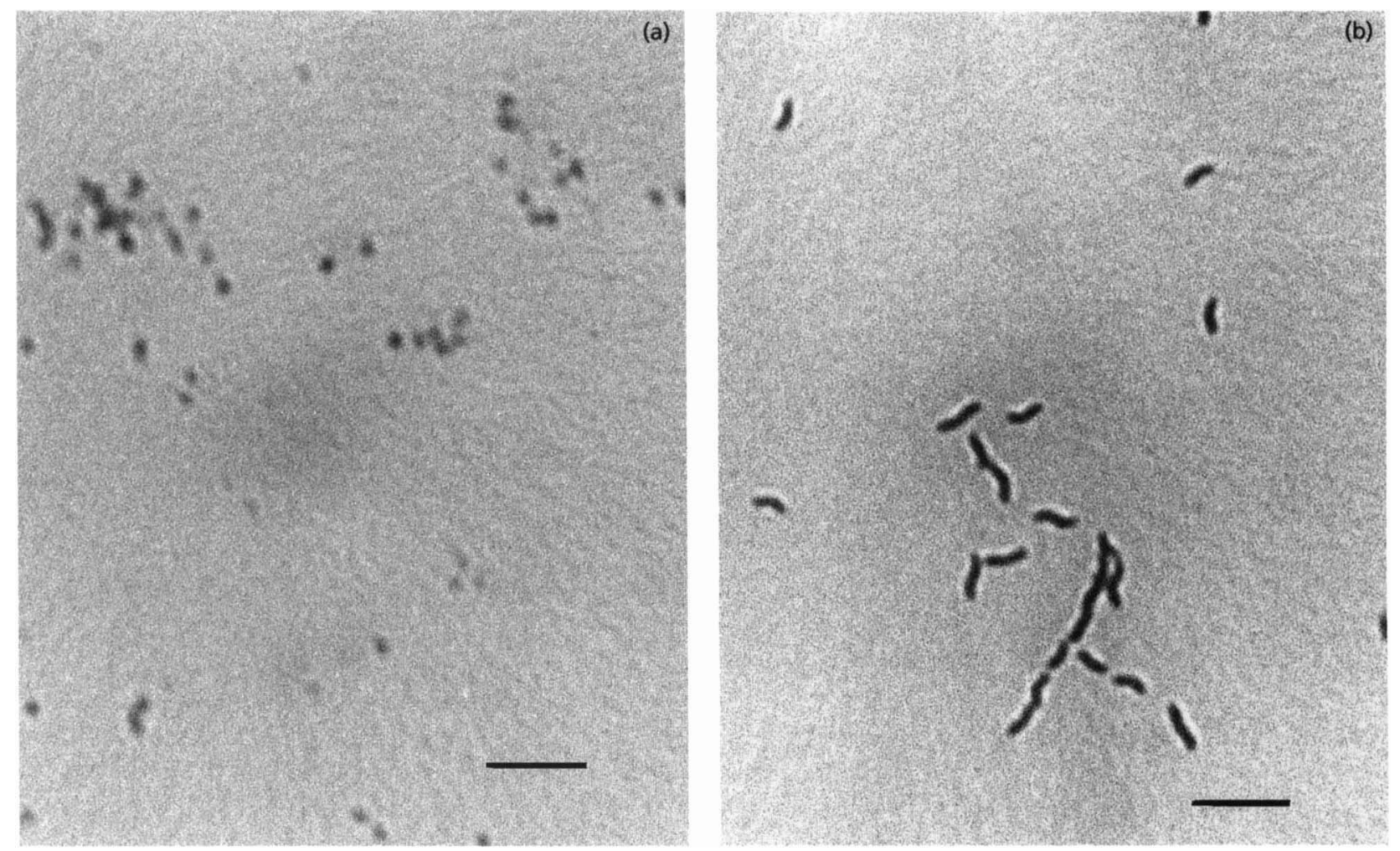

Fig. 2. Gram-stained samples of $C$. jejuni before (a) and after (b) regassing. Bar, $5 \mu \mathrm{m}$.

viable count' (DVC) are illustrated in Fig. 3. With C. jejuni 11351, DVC counts were approximately tenfold higher than plate counts at the start of gassing. Counts of metabolically active cells determined using the fluorogenic probe CTC were approximately 100 -fold higher than plate counts at the start of regassing. It was also evident that many of the cells containing fluorescent deposits were of coccoid morphology. Counts using the fluorescent nucleic acid stain DAPI were approximately the same as those obtained with CTC. This is noteworthy since DAPI is often used as a stain for total bacterial numbers rather than viable cells (Coleman, 1980; King \& Parker, 1988; Rodriguez et al., 1992).

During regassing, plate counts, CTC counts and DVC all increased but the differential between plate counts and either DVC or CTC counts was maintained, such that maxima were achieved in the order CTC count, DVC and plate count.

\section{Growth in spent broth}

To determine whether spent broth could support growth, cells from exponentially growing cultures of $C$. jejuni 11351 and 11168 were inoculated into sterile filtered spent broth, taken from cultures about to undergo regassing, and incubated at $39^{\circ} \mathrm{C}$ in the VAIN cabinet. The exponential phase inoculum grew in the spent broth and a final cell yield of about half that achieved in fresh broth was obtained with a doubling time during the exponential phase $\left(10^{5}-10^{8}\right.$ c.f.u. $\left.\mathrm{ml}^{-1}\right)$ of $1.1 \mathrm{~h}$ compared with $0.8 \mathrm{~h}$ in fresh broth. 


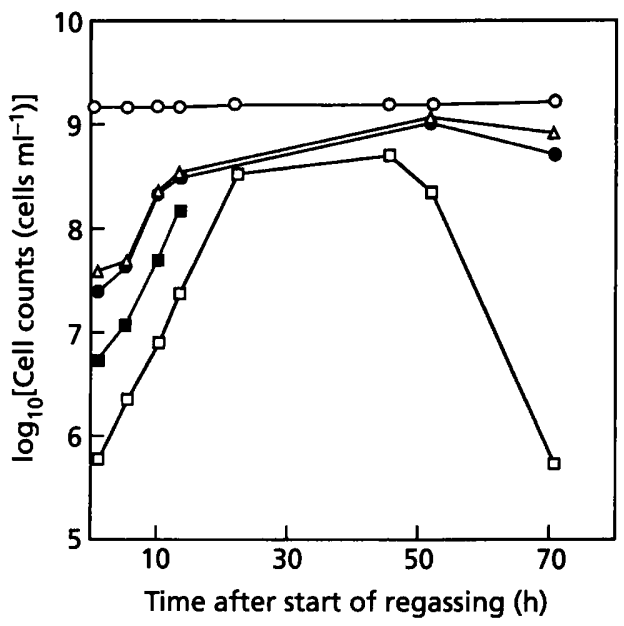

Fig. 3. Comparison of viable cell numbers determined by plate counting with those determined using other methods on regassing a culture of $C$. jejuni 11351. $\square$, Plate counts; $\square$, Kogure counts; $O$, total cell counts; $\triangle$, cell counts (DAPI); $\boldsymbol{Q}$, metabolically active cells (CTC).

\section{MPN methods}

The number of cells able to grow on plates formed only a very small proportion of the total population and would be greatly outnumbered by the putative VBNC cells. If the culture were serially diluted before regassing it would be possible to obtain tubes at the higher dilutions that statistically contained only VBNC cells. If growth was observed in these tubes after regassing then this would provide good evidence of the existence of dormant or 'not readily culturable' cells.

When dilutions were performed aerobically in microtitre plates followed by microaerophilic incubation, the MPN counts in fresh broth and fresh broth containing $0.2 \%$ mucin were up to 10 -fold and 23-fold higher, respectively, than plate counts (Table 2). Under the same conditions, the MPN counts in spent culture medium were only up to fivefold higher than the corresponding plate counts. Of the other conditions and supplements examined, only filtered exponential phase broth (13-fold increase) and fresh broth containing $1 \mathrm{mM}$ Br-cGMP (sevenfold increase) gave substantially higher results than plate counting.
It was also observed that plate counts from dilution tubes did not decrease in a logarithmic fashion but were of the same order from positive tubes. This indicated that some regrowth must have occurred in the regassed cultures.

\section{DISCUSSION}

The ability of spent broth to support growth shows that cessation of cell replication in the original culture was not caused solely by depletion of nutrients in the medium. Other factors that may be involved include oxygen limitation and the production of inhibitory metabolic products or pheromones in dense cultures. These possibilities are currently being investigated.

When gassing is discontinued and the system sealed there is a much more rapid decrease in plateable numbers than in continuously gassed cultures, which show a slow steady decline (data not shown). This rapid fall in plateability is probably mostly due to the swift decrease in oxygen levels within the culture on cessation of gassing, but the build-up of inhibitory volatile metabolic products that are removed by sparging may be a contributing factor. Again, this matter is the subject of further investigations.

Comparison of MPN counts with plate counts showed that recovery in liquid medium was always slightly better than on agar plates. Similar observations have been reported for cells injured by heat or other stresses (Mackey \& Derrick, 1982). However, recovery of C. jejuni in liquid media was further enhanced by adding mucin. Fucose did not have such a stimulatory effect and it appears, therefore, that it is not the chemoattractant property alone that enhances recovery. It is not yet clear whether the improved recovery in liquid media is caused by more favourable physicochemical conditions (e.g. redox potential, moisture or carbon dioxide tension) or whether there are specific effects.

The difference between MPN counts and plate counts is compelling evidence that resuscitation had occurred in filtered spent broth incubated under microaerophilic conditions. Cells capable of growth on plates would only be present in the lower dilutions, hence growth in tubes at greater dilutions must have arisen from cells that were unable to grow on plates. Since high cell numbers were detected by plate counts in MPN dilution tubes that initially contained only a few recoverable

Table 2. Comparison of viable counts by plate counting and MPN

\begin{tabular}{|lcccc|}
\hline Medium & $\begin{array}{c}\text { Replicate } \\
\text { expts }\end{array}$ & \multicolumn{3}{c|}{$\begin{array}{c}\text { Increase in MPN viable counts } \\
\text { compared with plate counts (-fold) }\end{array}$} \\
\cline { 3 - 5 } & & Minimum & Maximum & Mean \\
\hline Fresh broth & 7 & 1.3 & 10.4 & 3.7 \\
Fresh broth + mucin & 5 & 1.2 & 22.7 & 6.6 \\
Filtered spent broth & 8 & 0.7 & 5.3 & 2.6 \\
\hline
\end{tabular}


cells, multiplication must have occurred in these tubes following resuscitation. It seems likely that a similar pattern would occur during regassing of a bulk culture and the observed increase in count, therefore, probably reflects both resuscitation and regrowth.

MPN counts and plate counts differed by up to 23 -fold. This was of the same order as those obtained with the DVC method but somewhat lower than counts obtained with the fluorogenic indicator CTC. It may well be that further refinements of DVC and MPN recovery media would produce results more in line with those using CTC, although it is unwise to assume a direct correspondence between viability and metabolic activity. The numbers obtained using DAPI were expected to reflect total cell numbers and the gross underestimation suggests that under our conditions the dye was only taken up by viable cells.

Although it has been shown that non-plateable cells were present in the regassed cultures, it is still not readily apparent whether these are vibrioids or cocci. Hazeleger et al. (1995) showed that inhibition of protein synthesis by chloramphenicol or DNA damage caused by gamma irradiation did not prevent formation of coccoid cells, and concluded that the process was not an active one. However, they observed that the characteristics of coccoid cells depended on the conditions under which they were formed and suggested that coccoid cells formed at $4{ }^{\circ} \mathrm{C}$, which were similar in composition to vibrioid cells, might well play a role in the contamination cycle of C. jejuni. The presence of fluorescent formazan deposits in coccoid cells has previously been noted by Boucher et al. (1994). These authors commented that this was perhaps the best evidence for the continuing vitality of coccoid cells but concluded nevertheless that they represented a degenerate stage rather than a dormant state of the organism.

Our experiments clearly demonstrated that a proportion of surviving cells in aged cultures were in an injured or latent state that prevents growth on agar plates. It is possible that the size of this fraction is greater than we have been able to demonstrate and that much higher recoveries would be obtained under other recovery conditions (Humphrey, 1989). Nevertheless, from presently available evidence we must conclude that the size of the latent fraction is quite small and that most of the increase in count that occurs on regassing a spent culture comes from multiplication of residual viable cells.

\section{ACKNOWLEDGEMENTS}

We thank the Ministry of Agriculture, Fisheries and Food for financial support for this work.

\section{REFERENCES}

Aono, R., Yamasaki, M. \& Tamura, G. (1978). Changes in composition of envelope proteins in adenylate cyclase- or cyclic AMP receptor protein-deficient mutants of Escherichia coli. $J$ Bacteriol 136, 812-814.

Beumer, R. R., de Vries, J. \& Rombouts, F. M. (1992). Campylo- bacter jejuni non-culturable coccoid cells. Int J Food Microbiol 15, 153-163.

Bode, G., Mauch, F. \& Malfertheiner, P. (1993). The coccoid forms of Helicobacter pylori. Criteria for their viability. Epidemiol Infect 111, 483-490.

Boucher, S. N., Slater, E. R., Chamberlain, A. H. L. \& Adams, M. R. (1994). Production and viability of coccoid forms of Campylobacter jejuni. J Appl Bacteriol 77, 303-307.

Bovill, R. A., Shallcross, A. M. \& Mackey, B. M. (1994). Comparison of the fluorescent redox dye 5-cyano-2,3-ditolyltetrazolium chloride with $\mathrm{p}$-iodonitrotetrazolium violet to detect metabolic activity in heat-stressed Listeria monocytogenes cells. J Appl Bacteriol 77, 353-358.

Coleman, A. W. (1980). Enhanced detection of bacteria in natural environments by fluorochrome staining of DNA. Limnol Oceanogr 25, 948-951.

Colwell, R. R., Brayton, P. R., Grimes, D. J., Roszak, D. B., Huq, S. A. \& Palmer, L. M. (1985). Viable but non-culturable Vibrio cholerae and related pathogens in the environment: implications for release of genetically engineered microorganisms. Bio/Technology 3, 817-820.

Csaba, G. (1994). Phylogeny and ontogeny of chemical signalling: origin and development. Int Rev Cytol 155, 1-48.

Hazeleger, W. C., Janse, J. D., Koenraad, P. M. F. J., Beumer, R. R., Rombouts, F. M. \& Abee, T. (1995). Temperature-dependent membrane fatty acid and cell physiology changes in coccoid forms of Campylobacter jejuni. Appl Environ Microbiol 61, 2713-2719.

Hugdahl, M. B., Beery, J. T. \& Doyle, M. P. (1988). Chemotactic behaviour of Campylobacter jejuni. Infect Immun 56, 1560-1566.

Humphrey, T. J. (1989). An appraisal of the efficacy of preenrichment for the isolation of Campylobacter jejuni from water and food. J Appl Bacteriol 66, 119-126.

Jacob, J., Martin, W. \& Holler, C. (1993). Characterization of viable but nonculturable stage of $C$. coli, characterized with respect to electron microscopic findings, whole cell protein and lipooligosaccharide (LOS) patterns. Z Mikrobiol 148, 3-10.

Jones, D. M., Sutcliffe, E. M. \& Curry, A. (1991). Recovery of viable but non-culturable Campylobacter jejuni. J Gen Microbiol 137, 2477-2482.

Kaprelyants, A. S., Mukamolova, G. V. \& Kell, D. B. (1994). Estimation of dormant Micrococcus luteus cells by penicillin lysis and by resuscitation in cell-free spent culture medium at high dilution. FEMS Microbiol Lett 115, 347-352.

King, L. K. \& Parker, B. C. (1988). A simple, rapid method for enumerating total viable and metabolically active bacteria in ground water. Appl Environ Microbiol 54, 1630-1631.

Kogure, K., Simidu, U. \& Taga, N. (1979). A tentative direct microscopic method for counting living marine bacteria. Can J Microbiol 25, 415-420.

Lange, R. \& Hengge-Aronis, R. (1991). Growth phase regulated expression of bolA and morphology of stationary phase Escherichia coli cells are controlled by the novel sigma factor Sigma-S. J Bacteriol 173, 4474-4481.

Mackey, B. M. \& Derrick, C. M. (1982). A comparison of solid and liquid media for measuring the sensitivity of heat-injured Salmonella typhimurium to selenite and tetrathionate media, and the time needed to recover resistance. J Appl Bacteriol 53, 233-242.

Medema, G. J., Schets, F. M., van de Giessen, A. W. \& Havelaar, A. H. (1992). Lack of colonization of 1 day old chicks by viable, non-culturable Campylobacter jejuni. J Appl Bacteriol 72, 512516. 
Moran, A. P. \& Upton, M. E. (1987a). Effect of medium supplements, illumination and superoxide dismutase on the production of coccoid forms of Campylobacter jejuni ATCC 294228. J Appl Bacteriol 62, 43-51.

Moran, A. P. \& Upton, M. E. (1987b). Factors affecting production of coccoid forms by Campylobacter jejuni on solid media during incubation. J Appl Bacteriol 62, 527-537.

Mukamolova, G. V., Kaprelyants, A. S. \& Kell, D. B. (1995). Secretion of an antibacterial factor during resuscitation of dormant cells in Micrococcus luteus cultures held in an extended stationary phase. Antonie Leeuwenboek 67, 289-295.

Nilsson, L., Oliver, J. D. \& Kjelleberg, S. (1991). Resuscitation of Vibrio vulnificus from the viable but nonculturable state. $J$ Bacteriol 173, 5054-5059.

Oliver, J. D., Nilsson, L. \& Kjelleberg, S. (1991). Formation of nonculturable Vibrio vulnificus cells and its relationship to the starvation state. Appl Environ Microbiol 57, 2640-2644.

Oliver, J. D., Hite, F., McDougald, D., Andon, N. L. \& Simpson, L. M. (1995). Entry into, and resuscitation from, the viable but nonculturable state by Vibrio vulnificus in an estuarine environment. Appl Environ Microbiol 61, 2624-2630.

Rasmussen, L., Christensen, S. T., Schousboe, P. \& Wheatley, D. N. (1996). Cell survival and multiplication. The overriding need for signals: from unicellular to multicellular systems. FEMS Microbiol Lett 137, 123-128.

Rhoades, H. E. (1954). The illustration of the morphology of Vibrio fetus by electron microscopy. Am J Vet Res 15, 630-633.
Rodriguez, G. G., Phipps, D., Ishiguro, K. \& Ridgway, H. F. (1992). Use of a fluorescent redox probe for direct visualization of actively respiring bacteria. Appl Environ Microbiol 58, 18011808.

Rollins, D. M. \& Colwell, R. R. (1986). Viable but nonculturable stage of Campylobacter jejuni and its role in survival in the natural aquatic environment. Appl Environ Microbiol 52, 531538.

Saha, S. K., Saha, S. \& Sanyal, S. C. (1991). Recovery of injured Campylobacter jejuni cells after animal passage. Appl Environ Microbiol 57, 3388-3389.

Stern, N. J., Jones, D. M., Wesley, I. V. \& Rollins, D. M. (1994). Colonization of chicks by non-cultureable Campylobacter spp. Lett Appl Microbiol 18, 333-336.

Votyakova, T. V., Kaprelyants, A. S. \& Kell, D. B. (1994). Influence of viable cells on the resuscitation of dormant cells in Micrococcus luteus cultures held in an extended stationary phase: the population effect. Appl Environ Microbiol 60, 3284-3291.

Weichart, D. \& Kjelleberg, S. (1996). Stress resistance and recovery potential of culturable and viable but nonculturable cells of Vibrio vulnificus. Microbiology 142, 845-853.

Weichart, D., Oliver, J. D. \& Kjelleberg, S. (1992). Low temperature induced non-culturability and killing of Vibrio vulnificus. FEMS Microbiol Lett 100, 205-210.

Received 19 September 1996; revised 16 December 1996; accepted 2 January 1997. 